\title{
Fetal Brain-Sparing, Postnatal Cerebral Oxygenation, and Neurodevelopment at 4 Years of Age Following Fetal Growth Restriction
}

\section{OPEN ACCESS}

Edited by:

Hans Fuchs,

University of Freiburg, Germany

Reviewed by:

Berndt Urlesberger,

Medical University of Graz, Austria

Georg Schmolzer,

University of Alberta, Canada

*Correspondence:

Anne E. Richter

a.e.richter@umcg.nl

Specialty section:

This article was submitted to

Neonatology,

a section of the journal

Frontiers in Pediatrics

Received: 07 March 2020

Accepted: 15 April 2020

Published: 06 May 2020

Citation:

Richter AE, Salavati S, Kooi EMW,

Heijer AEd, Foreman $A B$,

Schoots $\mathrm{MH}$, Bilardo $\mathrm{CM}$,

Scherjon SA, Tanis JC and Bos AF (2020) Fetal Brain-Sparing, Postnatal

Cerebral Oxygenation, and

Neurodevelopment at 4 Years of Age

Following Fetal Growth Restriction.

Front. Pediatr. 8:225.

doi: 10.3389/fped.2020.00225

\begin{abstract}
Anne E. Richter ${ }^{1 *}$, Sahar Salavati ${ }^{1}$, Elisabeth M. W. Kooi ${ }^{1}$, Anne E. den Heijer ${ }^{1}$, Anne B. Foreman ${ }^{1}$, Mirthe H. Schoots ${ }^{2}$, Caterina M. Bilardo ${ }^{3,4}$, Sicco A. Scherjon ${ }^{3}$, Jozien C. Tanis ${ }^{3}$ and Arend F. Bos ${ }^{1}$

1 University of Groningen, University Medical Center Groningen, Beatrix Children's Hospital, Division of Neonatology, Groningen, Netherlands, ${ }^{2}$ University of Groningen, University Medical Center Groningen, Department of Obstetrics and Gynecology, Groningen, Netherlands, ${ }^{3}$ University of Groningen, University Medical Center Groningen, Department of Pathology and Medical Biology, Groningen, Netherlands, ${ }^{4}$ Department of Obstetrics and Gynecology, Amsterdam University Medical Center, VU University Medical Center, Amsterdam, Netherlands
\end{abstract}

Objectives: To assess the role of fetal brain-sparing and postnatal cerebral oxygen saturation $\left(\mathrm{r}_{\mathrm{C}} \mathrm{SO}_{2}\right)$ as determinants of long-term neurodevelopmental outcome following fetal growth restriction (FGR).

Methods: This was a prospective follow-up study of an FGR cohort of 41 children. Prenatally, the presence of fetal brain-sparing (cerebroplacental ratio $<1$ ) was assessed by Doppler ultrasound. During the first two days after birth, $\mathrm{r}_{\mathrm{C}} \mathrm{SO}_{2}$ was measured with near-infrared spectroscopy. At 4 years of age, intelligence (IQ points), behavior (T-scores), and executive function (T-scores) were assessed using the Wechsler Preschool and Primary Scale of Intelligence, Child Behavior Checklist, and Behavior Rating Inventory of Executive Function-Preschool Version, respectively. Using linear regression analyses, we tested the association $(\rho<0.05)$ between brain-sparing $/ \mathrm{r}_{\mathrm{C}} \mathrm{SO}_{2}$ and normed neurodevelopmental scores.

Results: Twenty-six children (gestational age ranging from 28.0 to 39.9 weeks) participated in the follow-up at a median age of 4.3 (range: 3.6 to 4.4) years. Autism spectrum disorder was reported in three children (11.5\%). Fetal brain-sparing was associated with better total and externalizing behavior (betas: -0.519 and -0.494 , respectively). $\mathrm{R}_{\mathrm{c}} \mathrm{SO}_{2}$ levels above the lowest quartile, particularly on postnatal day 2 ( $\geq 77 \%)$, were associated with better total and internalizing behavior and executive functioning (betas: $-0.582,-0.489$, and -0.467 , respectively), but also lower performance IQ (beta: -0.530). Brain-sparing mediated some but not all of these associations.

Conclusions: In this FGR cohort, fetal brain-sparing and high postnatal $\mathrm{r}_{\mathrm{C}} \mathrm{SO}_{2}$ were-independently, but also as a reflection of the same mechanism-associated with better behavior and executive function. Postnatal cerebral hyperoxia, however, was negatively associated with brain functions responsible for performance IQ.

Keywords: fetal doppler, cerebroplacental ratio, fetal brain-sparing, near-infrared spectroscopy, regional cerebral oxygen saturation, intelligence, behavior, executive function 


\section{INTRODUCTION}

Fetal growth restriction (FGR) has been associated with altered brain structure and adverse neurodevelopmental outcome (13). In addition to an increased risk for preterm delivery, which poses a risk on neurodevelopmental outcome itself, FGR fetuses experience hemodynamic redistribution of their cardiac output $(4,5)$. Although this redistribution with preferential perfusion of the brain (brain-sparing) can be considered a protective compensatory response to placental insufficiency, it is also a sign of fetal compromise $(6,7)$. Numerous studies have associated brain-sparing with an increased risk of adverse perinatal outcome in both early and late onset $\operatorname{FGR}(8,9)$. However, whether fetal brain-sparing is also associated with longterm neurodevelopmental delay is still under debate (10-13).

In addition to circulatory compromise in utero, FGR infants are susceptible to postnatal hemodynamic instability $(14,15)$. Organ immaturity associated with intrauterine nutrient deficiency and preterm birth, patent ductus arteriosus (PDA), maternal medication, and inotropic therapy interfere with adequate cerebral tissue oxygenation (16-18). Moreover, brain-sparing has been associated with impaired cerebral autoregulation, predisposing to fluctuations in blood flow and oxygenation (19). Evidence suggests that both postnatal cerebral hypo- and hyperoxia are associated with brain injury and neurodevelopmental delay $(20,21)$.

Despite intensive research in this field, studies evaluating fetal brain-sparing and/or postnatal cerebral oxygen saturation in relation to long-term neurodevelopmental outcome in FGR fetuses are scarce. Moreover, the extent to which both contribute to neurodevelopmental outcome following FGR has not been studied yet. We therefore aimed to longitudinally explore the effect of both fetal brain-sparing and postnatal cerebral oxygen saturation $\left(\mathrm{r}_{\mathrm{c}} \mathrm{SO}_{2}\right)$ on intelligence, behavior, and executive functioning (EF) in 4-year-old children with fetal growth restriction. We hypothesized that fetal brain-sparing and postnatal cerebral hypo- but also hyperoxia independently and cumulatively contribute to neurodevelopmental delay.

\section{MATERIALS AND METHODS}

\section{Study Design and Population}

This was a prospective follow-up study of an FGR cohort born between June 2012 and May 2014 in the University Medical Center Groningen (UMCG), The Netherlands. All children in this cohort were recruited antenatally, based on FGR defined as a fetal abdominal circumference or estimated fetal weight below the 10th percentile or a deflecting fetal growth curve by more than 30 percentiles compared with the previous examination. Exclusion criteria were structural or chromosomal abnormalities, multiple pregnancy, or evidence of intrauterine infection. Surviving infants with available fetal Doppler and/or neonatal $\mathrm{r}_{\mathrm{c}} \mathrm{SO}_{2}$ measurements on the first two days after birth were eligible for follow-up at 4 years of age, if consent for follow-up was given at prenatal inclusion. Children insufficiently mastering the Dutch language due to upbringing with another language were excluded from intelligence testing as this may negatively affect test results. The study was approved by the
Institutional Ethics Committee and written informed consent was obtained in all cases.

\section{Fetal and Neonatal Measurements}

Upon diagnosis of FGR, fetal hemodynamic parameters were measured at least once a week (twice upon admission) by Doppler sonography, including the pulsatility index (PI) of the umbilical artery (UA), the middle cerebral artery (MCA), and the ductus venosus (DV). The cerebroplacental ratio (CPR) was calculated by dividing the PI of the MCA by that of the UA. A CPR < 1 was defined as fetal brain-sparing (22). An abnormal flow in the DV was defined as a PI $>95$ th percentile or an absent or reversed a-wave. The last measurement before birth was used for analysis.

On day 1 and 2 after birth, we measured the $\mathrm{r}_{\mathrm{c}} \mathrm{SO}_{2}$ with near-infrared spectroscopy using the INVOS 5100C device and the neonatal OxyAlert Sensor (Medtronic, Dublin, Ireland). The sensor was placed on the right or left frontoparietal side of the head for a minimum of two hours per day. Data were retrieved at five-second intervals.

\section{Neurodevelopmental Follow-up at 4 Years}

At 4 years of age, the Wechsler Preschool and Primary Scale of Intelligence for children aged 4 to 7 years (WPPSI, 3rd edition) was performed. The following core subtests were tested to retrieve the full scale intelligence quotient (FSIQ), verbal IQ (VIQ), and performance IQ (PIQ): block design, information, matrix reasoning, vocabulary, picture concepts, word reasoning, and coding (23). If a child had previously been tested, we asked permission to use these test results as repetition can improve outcome and introduce bias. An IQ score $<85$ (one standard deviation below the mean) was defined below average. Failure to derive an IQ score due to inadequate responses was treated as missing data.

To assess behavior and EF, two parent-reported questionnaires were applied: the Child Behavior Checklist (CBCL) for ages 1.5-5 years and the Behavior Rating Inventory of Executive FunctionPreschool Version (BRIEF-P) for children aged 2-5 years. The CBCL comprised questions regarding internalizing behavior (emotional reactivity, anxiety/depression, somatic complaints, and withdrawal), externalizing behavior (attention and aggressive behavior), and sleep problems, which together constituted a total behavior scale (24). The BRIEF-P allowed for calculation of the Inhibitory Self-Control Index (ISCI, i.e., the child's ability to adjust its behavior using appropriate inhibitory self-control), the Flexibility Index (FI, i.e., the child's capacity to adapt to change), the Emergent Metacognition Index (EMI, i.e., the child's capacity to effectively solve problems using working memory and planning), and a total EF score comprising all three indices (25). For both CBCL and BRIEF-P normed T-scores were calculated. Abnormal scores were defined as T-scores $\geq 60$ and $\geq 65$, respectively.

\section{Patient Characteristics}

Available perinatal data with potential influence on fetal brainsparing, postnatal cerebral oxygenation, and neurodevelopment, such as maternal smoking, placental histology, gestational age (GA) at birth, birth weight (z-scores), head circumference at birth 
(z-score), Apgar score at $5 \mathrm{~min}$, arterial cord blood $\mathrm{pH}$ and base excess, the need for mechanical ventilation, a hemodynamically significant PDA, necrotizing enterocolitis, sepsis, and intracranial pathology were collected. At the age of 4 years, length, weight, and head circumference were measured and any sensory problems (visual acuity, hearing) were recorded. Additionally, we retrieved information on maternal socioeconomic status (based on educational background).

\section{Sample Size Calculation}

In a previous study, we reported that $39 \%$ of these FGR infants showed evidence of fetal brain-sparing, which was in turn significantly related to a higher postnatal cerebral oxygen saturation and abnormal general movements (GMs) at 1 week after birth $(26,27)$. Because the quality of GMs is closely related to IQ, which was found to be 15 points lower (i.e., 1 $\mathrm{SD}$ ) by Bruggink et al. if GMs were abnormal, we expected to find a 1 SD difference of IQ between children with and without fetal brain-sparing (28). For the individual child, this is a highly relevant difference. With a power of $80 \%$, an alpha of $5 \%$, and an experiment-to-control subjects ratio of 0.6 , at least 21 children needed to be included in the follow-up to reach statistical significance.

\section{Statistical Analysis}

The statistical software package SPSS 23.0 (IBM Corporation, Armonk, New York, USA) was used for analyses. First, we explored the association between $\mathrm{r}_{\mathrm{c}} \mathrm{SO}_{2}$ and the continuous neurodevelopmental outcome scales using Spearman's rank correlation analysis and scatterplots. Graphical data suggested a linear relationship with a potential $\mathrm{r}_{\mathrm{c}} \mathrm{SO}_{2}$ threshold for abnormal outcome scores between the first (lowest) and the second quartile (cut-off value of $72 \%$ for day 1 and $77 \%$ for day 2 ). Second, we performed separate linear regression analyses to examine the effect of (1) fetal brain-sparing and (2) postnatal $\mathrm{r}_{\mathrm{c}} \mathrm{SO}_{2}$ above the lowest quartile on the continuous neurodevelopmental outcome scales. Patient characteristics associated with both outcome and either fetal brain-sparing or postnatal $\mathrm{r}_{\mathrm{c}} \mathrm{SO}_{2}(p<0.1$ using Chi square, Mann-Whitney $U$, $t$-test, or Spearman's correlation) were regarded as confounders and adjusted for by adding them to the model. Third, we tested whether $\mathrm{r}_{\mathrm{c}} \mathrm{SO}_{2}$ was related to brainsparing using Mann-Whitney $U$ test. If so, brain-sparing was entered into the linear regression models for $\mathrm{r}_{\mathrm{c}} \mathrm{SO}_{2}$ to explore mediation. For regression analyses, a $p$-value below 0.05 was considered significant.

\section{RESULTS}

Out of 51 FGR infants, 48 survived the neonatal period and 41 were eligible for follow-up based on consent and perinatal measurements. At 4 years, three children were lost to follow-up due to lack of contact information or response, and the parents of 12 children withdrew consent to follow-up.

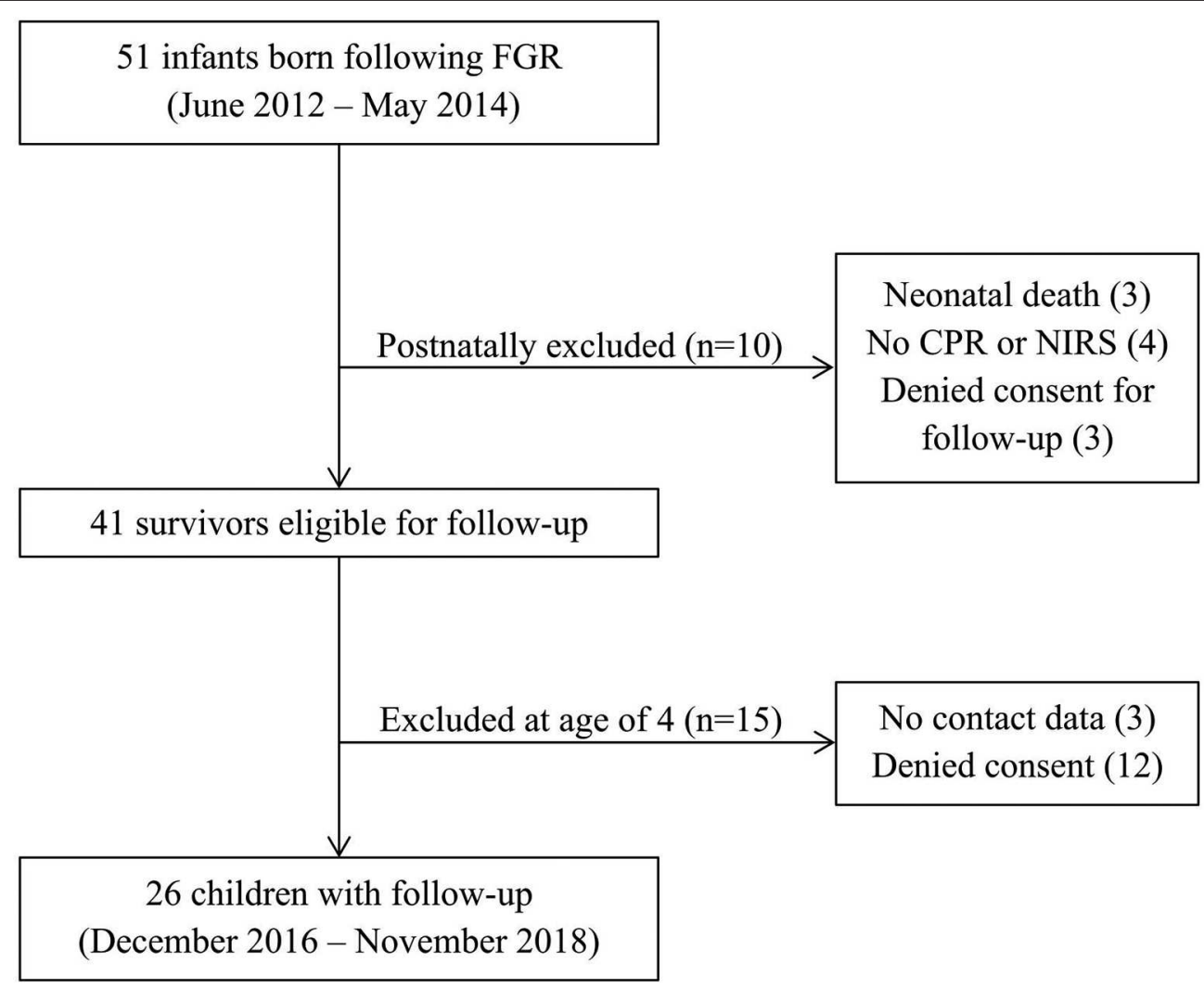

FIGURE 1 | Inclusion flowchart. CPR, cerebroplacental ratio; FGR, fetal growth restriction; NIRS, near-infrared spectroscopy. 
TABLE 1 | Cohort characteristics ( $n=26$, if not indicated otherwise).

n (\%) or median [range]

\section{Maternal characteristics}

Smoking during pregnancy

Preeclampsia

PPROM

Socioeconomic status

Low

Middle

High

Perinatal infant characteristics

Female

Abnormal flow UA (PI > 95th percentile or absent/reversed flow)

Abnormal flow MCA (PI $<5$ th percentile), measured in $n=25$

Fetal brain-sparing (CPR $<1)$, measured in $n=25$

Abnormal flow in the DV ( $\mathrm{PI}>95$ th percentile/absent or reversed a-wave), measured in $n=23$

Cesarean section

Gestational age, weeks

GA $<32$ weeks

Birth weight, z-score

Small-for-gestational age

Head circumference, z-score

Apgar score at $5 \mathrm{~min}$

Arterial cord blood $\mathrm{pH}$

Arterial cord blood BE (mmol/l)

Admission to NICU

Mechanical ventilation

Hemodynamically significant PDA

Neonatal sepsis

IVH/PVL

Transient PVE

Developmental characteristics at 4 years

Height, z-score

Weight, z-score

Head circumference, z-score

Suspected or diagnosed ASD

\section{Cognitive outcome at 4 years}

Full Scale IQ $(n=19)$

Verbal IQ $(n=19)$

Performance IQ $(n=20)$

\section{Behavioral outcome at 4 years (T-score)}

Total behavior $(n=25)$

Internalizing behavior $(n=25)$

Externalizing behavior $(n=25)$

Executive function at $\mathbf{4}$ years (T-score)

Total executive function $(n=24)$

Inhibitory Self-Control Index $(n=25)$

Flexibility index $(n=25)$

Emergent metacognition index $(n=24)$
$7(27)$

4 (15)

2 (8)

- -

$14(54)$

$11(42)$

12 (46)

$18(69)$

8 (31)

11 (44)

$13(56)$

$19(73)$

35.1 [28.0; 39.9]

$7(27)$

$-2.7[-5.9 ;-0.29]$

23 (89)

$-2.1[-4.3 ;-0.4]$

$8.5[4 ; 10]$

$7.26[7.92 ; 7.41]$

$-6[-11 ;-1]$

17 (65)

9 (35)

2 (8)

$1(4)$

5 (19)

-0.45 [-2.19; 3.40]

-0.93 [-2.68; 4.37$]$

-0.57 [-3.73; 2.09]

$3(12)$

Median [range]

94 [63; 123]

97 [71; 120]

94 [72; 120]

Median [range]

56 [28; 72]

55 [29; 73]

56 [28; 68]

Median [range]

$60[34 ; 76]$

$57[35 ; 77]$

58 [37; 95]

$55[36 ; 71]$
Below average (IQ <85)

4 (21)

4 (21)

3 (15)

Abnormal (T-score $\geq 60$ )

8 (32)

8 (32)

7 (28)

Abnormal (T-score $\geq 65$ )

9 (38)

8 (32)

6 (24)

7 (29)

Percentages were calculated based on number of total measurements, which may deviate from the number of included infants in this cohort as indicated. ASD, autism spectrum disorder (as reported by parents); a-wave, atrial contraction wave; BE, base excess; CPR, cerebroplacental ratio; DV, ductus venosus; GA, gestational age; IQ, intelligence quotient;

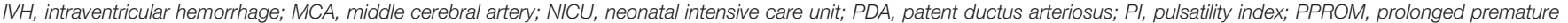
rupture of membranes (>12 h); PVE; periventricular echodensities; PVL, periventricular leukomalacia; UA, umbilical artery. 
Non-participants had a median GA of 34.4 [interquartile range (IQR) 29.3-38.4] weeks and a median birth weight z-score of -1.28 [IQR $-1.66--0.70$ ]. Eventually, 26 children participated in neurodevelopmental testing, conducted from December 2016 to November 2018. A detailed inclusion flowchart is depicted in Figure 1. Perinatal patient characteristics of children declining or lost to follow-up, such as gestational age, birth weight (z-score), head circumference (z-score), CPR (z-score), postnatal cerebral oxygen saturation, neonatal or gestational complications, were not significantly different from those of participating children (data not shown).

\section{Characteristics of Study Participants}

Detailed perinatal and childhood characteristics are given in Table 1. Seven infants (27\%) were born very preterm (i.e., $<32$ weeks GA). Seventeen infants (65\%) had been admitted to neonatal intensive care and nine infants $(35 \%)$ required mechanical ventilation. 22 children had an arterial cord blood $\mathrm{pH}$ $<7.35$, but none had an arterial cord blood $\mathrm{pH}<7.00$ and/or base excess $<-12$. Routine postnatal ultrasounds did not reveal major cerebral pathologies in any neonate.

The median age at follow-up was 4.3 (total range 3.64.4) years. No major health or neurosensory problems were recorded, but three children were parentally reported to be diagnosed with or highly suspected of autism spectrum disorder (ASD). One of them did not participate in the WPPSI and one had been tested by an external institution at the age of 3.6 years, whose results we were allowed to use. Another child did not participate in the WPPSI but only questionnaires, as the mother judged the infant not emotionally apt. In four children ( $15 \%$, including the third case of ASD), the WPPSI was largely unsuccessful (one resulting in only a valid PIQ but not VIQ/FSIQ score) due to severe concentration and/or behavioral problems or because tasks were not understood or reacted to appropriately. None of the four children showed fetal brainsparing and three had repeatedly low $\mathrm{r}_{\mathrm{c}} \mathrm{SO}_{2}$ levels $(56-75 \%)$ on both postnatal days.

\section{Fetal Brain-Sparing and Neurodevelopmental Outcome at 4 Years}

In 25 infants $(96 \%)$ the cerebroplacental ratio was available. In 11 infants (44\%) fetal brain-sparing was present during last prenatal ultrasound. Among the infants without brainsparing, seven versus nine infants demonstrated abnormal UA flow during last versus earlier prenatal ultrasound examinations. At least two infants without brain-sparing but abnormal UA flow during last prenatal ultrasound demonstrated brain-sparing during earlier ultrasound examinations. Their $\mathrm{r}_{\mathrm{c}} \mathrm{SO}_{2}$ levels were $66 \%$ and $71 \%$ on day 1 and $64 \%$ and $89 \%$ on day 2 , respectively. Placental histology was not significantly different between children with and without brain-sparing, except for a tendency toward a lower placental weight percentile in those with fetal brain-sparing (Table 2).

Children with fetal brain-sparing during last ultrasound had a lower median GA and were slightly but not significantly smaller and more acidotic at birth than children without brain-sparing (Table 2). There was no difference in neonatal complications. At
TABLE 2 | The presence or absence of fetal brain-sparing $(C P R<1)$ at last prenatal ultrasound in relation to placental histology, detailed fetal Doppler indices, and perinatal outcome.

\begin{tabular}{|c|c|c|c|}
\hline & $\begin{array}{c}\text { Fetal } \\
\text { brain-sparing } \\
n=11\end{array}$ & $\begin{array}{c}\text { No fetal } \\
\text { brain-sparing } \\
n=14\end{array}$ & $p$-value \\
\hline \multicolumn{4}{|l|}{ Placental histology ${ }^{\dagger}$} \\
\hline $\begin{array}{l}\text { Maternal vascular } \\
\text { underperfusion }\end{array}$ & $5(50)$ & $6(50)$ & 1.000 \\
\hline $\begin{array}{l}\text { Fetal thrombotic } \\
\text { vasculopathy }\end{array}$ & $4(40)$ & $3(25)$ & 0.452 \\
\hline $\begin{array}{l}\text { Ascending intrauterine } \\
\text { infection }\end{array}$ & $2(20)$ & $2(17)$ & 0.840 \\
\hline Chronic deciduitis & $4(40)$ & $4(33)$ & 0.746 \\
\hline $\begin{array}{l}\text { Villitis of unknown } \\
\text { etiology }\end{array}$ & $2(20)$ & $1(8)$ & 0.427 \\
\hline $\begin{array}{l}\text { Increase in nucleated } \\
\text { RBCs }\end{array}$ & $3(30)$ & $2(17)$ & 0.457 \\
\hline $\begin{array}{l}\text { Placental weight } \\
\text { (gram) }\end{array}$ & 262 [206; 436] & $321[149 ; 507]$ & 0.228 \\
\hline$<10$ th percentile & $9(90)$ & $7(58)$ & $0.097^{\star}$ \\
\hline \multicolumn{4}{|l|}{$\begin{array}{l}\text { Doppler } \\
\text { characteristics at } \\
\text { last prenatal } \\
\text { ultrasound }\end{array}$} \\
\hline $\begin{array}{l}\text { Abnormal flow UA (PI } \\
>\text { 95th percentile or } \\
\text { absent/reversed flow) }\end{array}$ & $11(100)$ & $7(50)$ & $0.006^{\star \star}$ \\
\hline $\begin{array}{l}\text { Abnormal flow MCA } \\
(\mathrm{PI}<5 \text { th percentile })\end{array}$ & $7(64)$ & $1(7)$ & $0.003^{\star \star}$ \\
\hline $\begin{array}{l}\text { Abnormal flow DV (PI } \\
>95 \text { th } \\
\text { percentile/absent or } \\
\text { reversed a-wave) }\end{array}$ & $7(64)$ & $6(43)$ & 0.510 \\
\hline \multicolumn{4}{|l|}{ Perinatal outcome } \\
\hline Cesarean delivery & $11(100)$ & $8(57)$ & $0.013^{\star \star}$ \\
\hline $\begin{array}{l}\text { Gestational age, } \\
\text { weeks }\end{array}$ & $\begin{array}{c}32.1[29.1 \\
37.6]\end{array}$ & $\begin{array}{c}36.2[28.0 ; \\
39.9]\end{array}$ & $0.085^{\star}$ \\
\hline$<32$ weeks & $5(46)$ & $2(14)$ & $0.085^{\star}$ \\
\hline Birth weight, z-score & $\begin{array}{c}-3.42[-5.36 \\
-1.79]\end{array}$ & $\begin{array}{c}-2.44[-5.87 \\
-0.29]\end{array}$ & $0.066^{\star}$ \\
\hline $\begin{array}{l}\text { Head circumference, } \\
\text { z-score }\end{array}$ & $\begin{array}{c}-1.86[-4.31 \\
-0.43]\end{array}$ & $\begin{array}{c}-2.12[-3.62 \\
-0.92]\end{array}$ & 0.687 \\
\hline Arterial cord blood pH & $\begin{array}{c}7.21[7.02 \\
7.31]\end{array}$ & $\begin{array}{c}7.28[7.16 \\
7.41]\end{array}$ & $0.075^{\star}$ \\
\hline $\begin{array}{l}\text { Arterial cord blood BE } \\
(\mathrm{mmol} / \mathrm{l})\end{array}$ & $-7[-11 ;-2]$ & $-6[-10 ;-1]$ & 0.515 \\
\hline
\end{tabular}

Data are given as medians [range] or numbers (\%). " and " present a difference between groups below the $5 \%$ and $10 \%$ significance level, respectively. ${ }^{\dagger}$ as examined in $n=$ 10 (fetal brain-sparing present) and $n=12$ (fetal brain-sparing absent) placentas by a perinatal pathologist according to the criteria applicable at the time of examination (4657). BE, base excess; $C P R$, cerebroplacental ratio; $D V$, ductus venosus; $M C A$, middle cerebral artery; UA, umbilical artery; PI, pulsatility index; RBC, red blood cell.

the age of 4 , one child with and two without fetal brain-sparing (but abnormal UA flow) during last ultrasound were diagnosed with ASD.

Figure 2 depicts the association between brain-sparing and neurodevelopmental outcomes. Fetal brain-sparing was not 


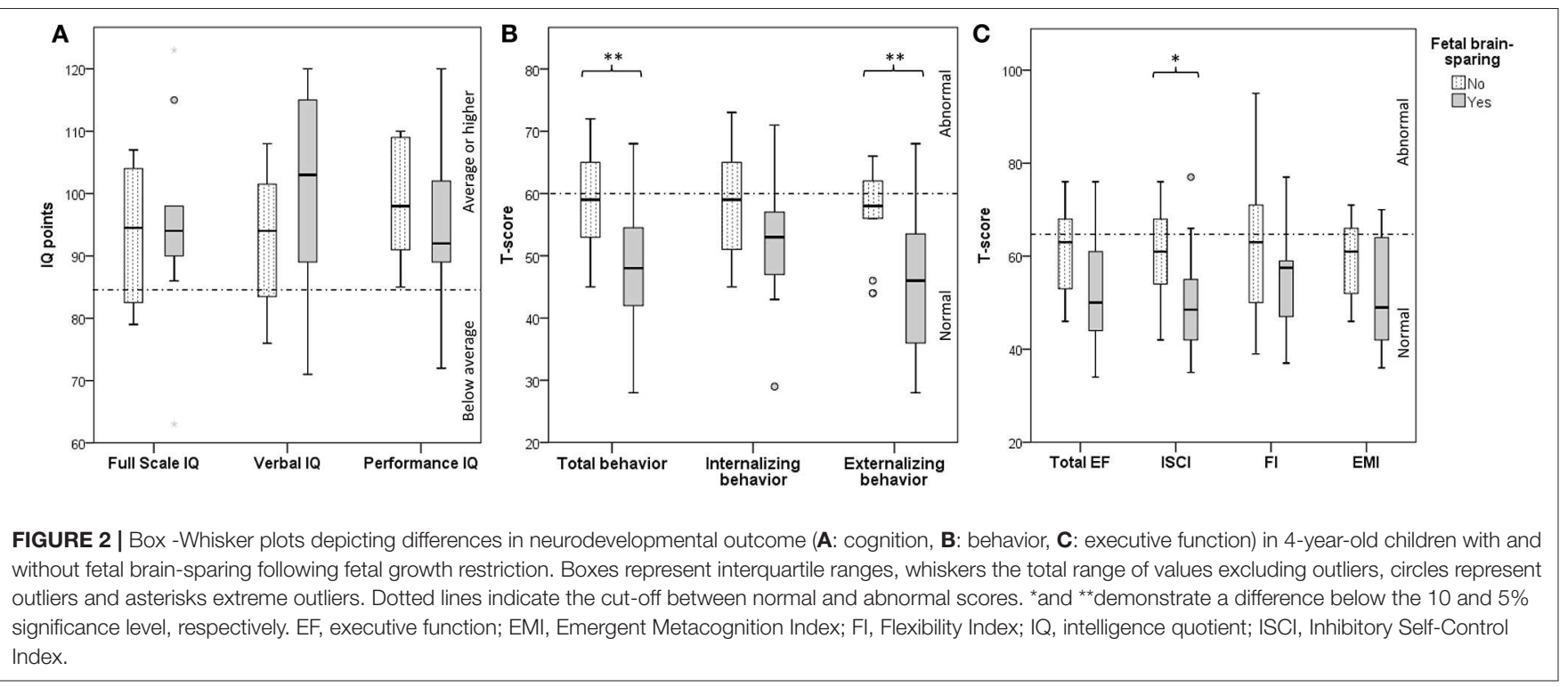

TABLE 3 | The association between fetal brain-sparing or the lowest quartile of cerebral tissue oxygen saturation on day 1 and 2 after birth and neurodevelopmental outcome at 4 years of age in children born following fetal growth restriction, using separate linear regression models.

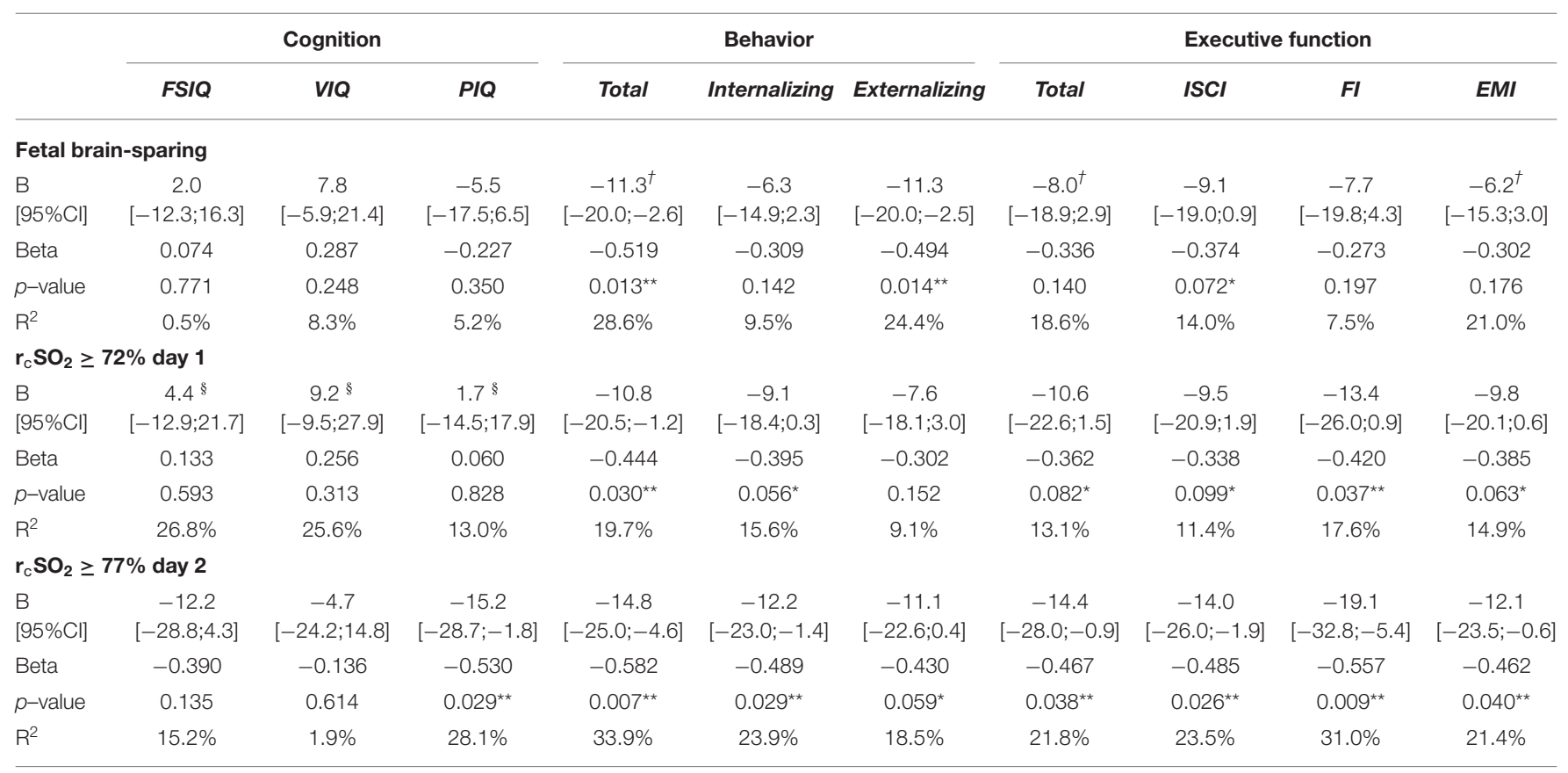

${ }^{\dagger}$ The association was adjusted for gestational age. ${ }^{\S}$ The association was adjusted for head circumference at birth (z-score). ${ }^{* *}$ and ${ }^{*}$ present an association below the $5 \%$ and $10 \%$ significance level, respectively. B, unstandardized coefficient; Beta, standardized coefficient; Cl, confidence interval; EMI, Emergent Metacognition Index; FI, Flexibility Index; FSIQ, Full Scale Intelligence Quotient; ISCI, Inhibitory Self-Control Index; PIQ, Performance Intelligence Quotient; $r_{C} \mathrm{SO}_{2}$, regional cerebral tissue oxygen saturation; $R^{2}$, Nagelkerke's $R$ squared (percentage of variance in outcome explained by either brain-sparing or $r_{C} \mathrm{SO}_{2}$ and adjusted confounders); VIQ, Verbal Intelligence Quotient.

associated with IQ (Table 3). It was, however, associated with better total behavior (i.e., a T-score of 11 points less than with absence of brain-sparing) and better externalizing behavior. Infants with fetal brain-sparing also tended to have better inhibitory self-control. If indicated, the association was adjusted for gestational age, which positively correlated with the T-scores for total behavior (Spearman's rho $=0.421$, $p=0.036$ ), total $\mathrm{EF}$ (rho $=0.410, p=0.046$ ), and EMI (rho $=0.480, p=0.018$ ).

Excluding the two cases with potential loss of brain-sparing (of which one was reported to have ASD) eliminated the trend association between brain-sparing and ISCI $(p>0.1)$ and reduced the strength of association between brain-sparing and better externalizing behavior $(0.05<p<0.1$, data not 

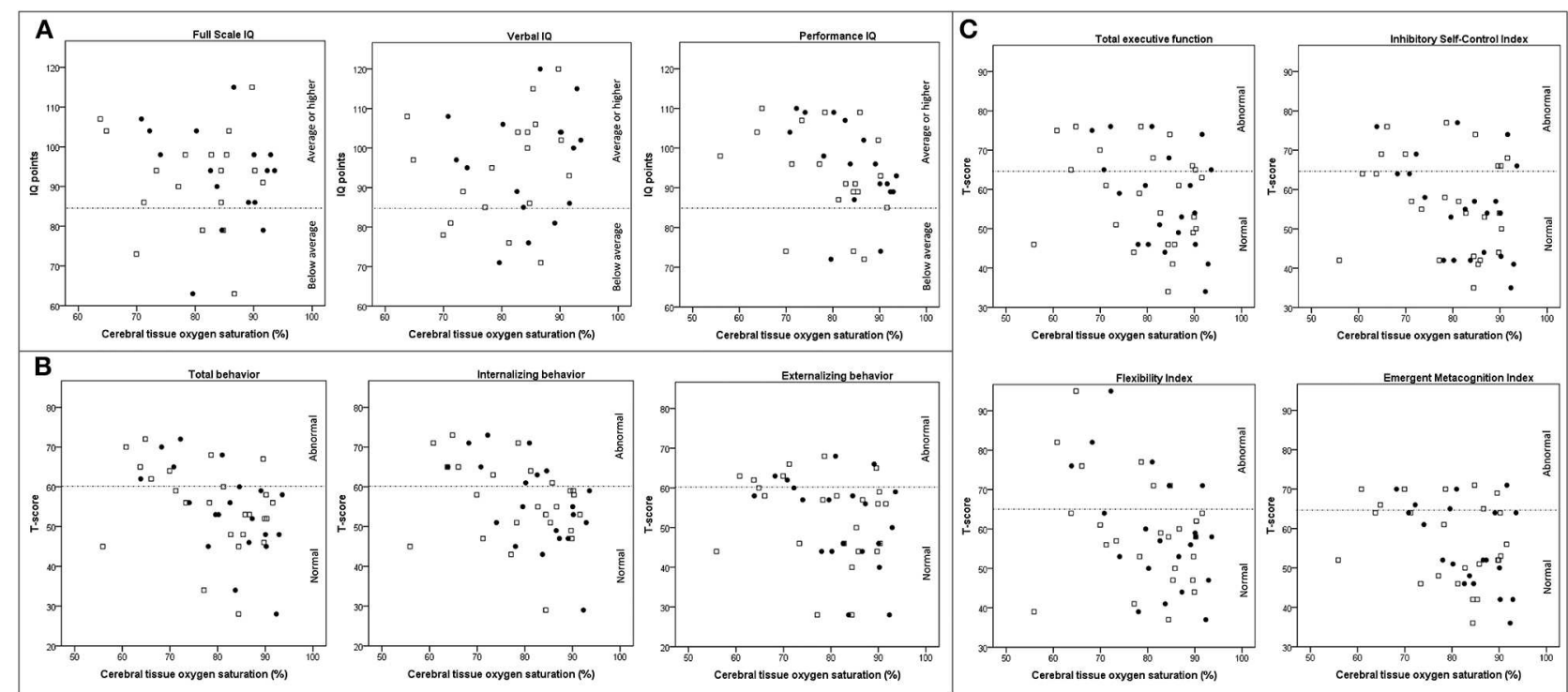

FIGURE 3 | Scatterplots depicting the association between cerebral oxygen saturation on postnatal day 1 (white squares), day 2 (black dots), and neurodevelopmental outcome (A: cognition, B: behavior, and $\mathbf{C}$ : executive function) in children at 4 years of age following fetal growth restriction. Dotted lines indicate the cut-off between normal and abnormal scores. IQ, intelligence quotient.

shown). Treating the two cases as brain-sparing, eliminated the association between brain-sparing, ISCI, and externalizing behavior, and reduced its strength of association with a better total behavior $(0.05<p<0.1$, data not shown).

To explore the impact of emerging fetal cardiac decompensation, we performed the same analyses with brain-sparing in combination with abnormal DV flow $(n=7)$. This was associated with a lower PIQ $(\mathrm{B}=-13.0,95 \% \mathrm{CI}=$ $-24.5--1.5, p=0.029)$, better total behavior $(B=-11.1,95 \%$ $\mathrm{CI}=-20.4--1.7, p=0.023)$, and better inhibitory self-control $(\mathrm{B}=-11.9,95 \% \mathrm{CI}=-22.3-1.5, p=0.026)$. There was also a tendency toward better externalizing behavior $(B=-9.0,95 \%$ $\mathrm{CI}=-19.3-1.3, p=0.084)$ and total $\mathrm{EF}(\mathrm{B}=-10.6,95 \% \mathrm{CI}$ $=-21.2-0.03, p=0.051)$. Adjustment for other variables was not indicated.

\section{Postnatal Cerebral Oxygen Saturation and Neurodevelopmental Outcome at 4 Years}

Cerebral $\mathrm{rSO}_{2}$ was measured in 25 infants. Average $\mathrm{r}_{\mathrm{c}} \mathrm{SO}_{2}$ ranged from 56 to $92 \%$ on day 1 (median $83 \%$, IQR $71-89 \%$ ) and from 64 to $94 \%$ on day 2 (median $84 \%$, IQR $76-90 \%$ ). It was not associated with GA at birth or birth weight, but $\mathrm{r}_{\mathrm{c}} \mathrm{SO}_{2}$ on day 1 positively correlated with head circumference $\mathrm{z}$-scores $(p<0.1)$. Among neonatal and maternal characteristics, only a PDA was significantly associated with lower $\mathrm{r}_{\mathrm{c}} \mathrm{SO}_{2}$ on both days $(p<0.1)$.

Figure 3 depicts a linear relationship between $r_{c} S_{2}$ and neurodevelopmental outcome. Correlation analyses confirmed that a higher $\mathrm{r}_{\mathrm{c}} \mathrm{SO}_{2}$ on day 2 but not day 1 was associated with lower PIQ, but better total and internalizing behavior and a tendency toward better emotional flexibility and emergent metacognition (i.e., lower T-scores, Table 4). As scatterplots suggested a potential $\mathrm{r}_{\mathrm{c}} \mathrm{SO}_{2}$ threshold toward abnormal IQ and
TABLE 4 | The association between cerebral tissue oxygen saturation $\left(\mathrm{r}_{\mathrm{C}} \mathrm{SO}_{2}\right)$ on day 1 and 2 after birth and neurodevelopmental outcome at 4 years of age in children born following fetal growth restriction, using Spearman's rank correlation analyses.

\begin{tabular}{|c|c|c|c|c|}
\hline & $\mathrm{r}_{\mathrm{C}} \mathrm{SO}_{2} \mathrm{C}$ & & $\mathrm{r}_{\mathrm{C}} \mathrm{SO}_{2} \mathrm{C}$ & \\
\hline & $\begin{array}{l}\text { Correlation } \\
\text { coefficient }\end{array}$ & $p$-value & $\begin{array}{l}\text { Correlation } \\
\text { coefficient }\end{array}$ & $p$-value \\
\hline Cognition (IC & & & & \\
\hline Full-Scale & -0.031 & 0.902 & -0.291 & 0.275 \\
\hline Verbal & 0.236 & 0.345 & 0.172 & 0.524 \\
\hline Performance & -0.370 & 0.119 & -0.603 & $0.010^{\star \star}$ \\
\hline $\begin{array}{l}\text { Behavior } \\
\text { (T-scores) }\end{array}$ & & & & \\
\hline Total & -0.342 & 0.102 & -0.554 & $0.011^{\star *}$ \\
\hline Internalizing & -0.267 & 0.207 & -0.528 & $0.017^{\star \star}$ \\
\hline Externalizing & -0.261 & 0.218 & -0.362 & 0.117 \\
\hline $\begin{array}{l}\text { Executive fu } \\
\text { (T-scores) }\end{array}$ & & & & \\
\hline Total & -0.216 & 0.310 & -0.370 & 0.108 \\
\hline $\mathrm{ISCl}$ & -0.184 & 0.378 & -0.355 & 0.114 \\
\hline $\mathrm{Fl}$ & -0.226 & 0.277 & -0.399 & $0.073^{*}$ \\
\hline EMI & -0.147 & 0.492 & -0.427 & $0.060^{*}$ \\
\hline
\end{tabular}

** and ${ }^{*}$ present an association below the $5 \%$ and $10 \%$ significance level, respectively. EMI, Emergent Metacognition Index; Fl, Flexibility Index; ISCI, Inhibitory Self-Control Index; IQ, Intelligence Quotient; $r_{C} \mathrm{SO}_{2}$, regional cerebral tissue oxygen saturation.

T-scores at around $70-80 \%$ for both days, we build a binary variable using the cut-off values between the lowest and the second lowest quartile ( $72 \%$ on day 1 and $77 \%$ on day 2 ), which was entered into regression analyses. $\mathrm{R}_{\mathrm{c}} \mathrm{SO}_{2}$ values equal 


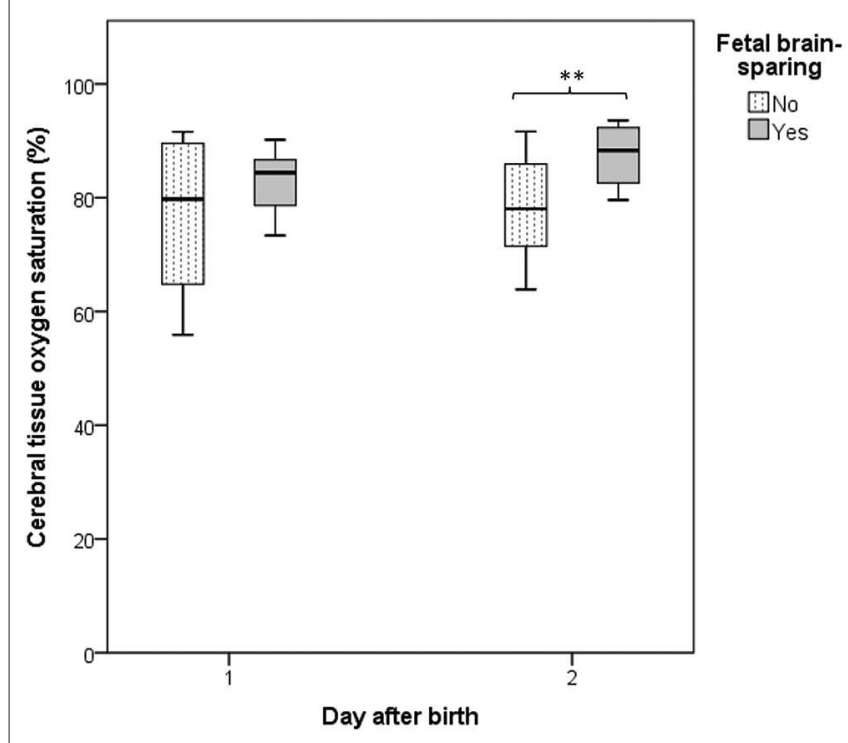

FIGURE 4 | Box-Whisker plot depicting the association between fetal brain-sparing and the cerebral oxygen saturation on postnatal days 1 and 2 in infants born following fetal growth restriction. Boxes represent interquartile ranges and whiskers the total range of values. ${ }^{* *}$ demonstrates a difference below the $5 \%$ significance level.

to or above $77 \%$ on day 2 were associated with worse PIQ, but better total and internalizing behavior, and better EF (all domains, Table 3). There was also a tendency toward better externalizing behavior. Moreover, $\mathrm{r}_{\mathrm{c}} \mathrm{SO}_{2}$ values equal to or above $72 \%$ on day 1 were associated with better total behavior and ability to adapt to change. There was also a tendency toward better internalizing behavior, total EF, inhibitory self-control, and emergent metacognition for values above the lowest quartile on day 1 .

Fetal brain-sparing was associated with higher $\mathrm{r}_{\mathrm{c}} \mathrm{SO}_{2}$ on postnatal day $2(p=0.020$, Figure 4$)$. Forcing both into one regression model, the majority of associations disappeared or reduced in strength, further supporting mediation between the two variables. Only $\mathrm{r}_{\mathrm{c}} \mathrm{SO}_{2}$ levels above the lowest quartile remained associated with better emotional flexibility $(\mathrm{B}=-18.8$, 95\% CI $=-35.5--2.5, p=0.029)$ and a tendency toward better total and internalizing behavior $(\mathrm{B}=-11.6,95 \% \mathrm{CI}=$ $-25.0-1.8, p=0.084$, and $\mathrm{B}=-12.2,95 \% \mathrm{CI}=-25.9-1.4, p$ $=0.077)$.

\section{DISCUSSION}

In this follow-up study of FGR infants, fetal brain-sparing was not associated with IQ at 4 years, but with better total and externalizing behavior. Similarly, postnatal $\mathrm{r}_{\mathrm{c}} \mathrm{SO}_{2}$ above the lowest quartile on day 1 and 2 were associated with better total and internalizing behavior and executive functioning. However, the opposite was true for the association between PIQ and $\mathrm{r}_{\mathrm{c}} \mathrm{SO}_{2}$ levels on postnatal day 2. Brain-sparing, which greatly influenced $\mathrm{r}_{\mathrm{c}} \mathrm{SO}_{2}$ levels on day 2, seemed to mediate some but not all associations between $\mathrm{r}_{\mathrm{c}} \mathrm{SO}_{2}$ and outcome.
Other studies have evaluated the effect of brain-sparing on long-term neurodevelopment in FGR children. Korkalainen et al. reported that, adjusted for GA, only abnormal umbilical or DV flow, but not a low CPR were associated with a need for physiotherapy, special education, or speech therapy at 9 years (29). Bellido-Gonzalez et al. reported that, in comparison with appropriate-for-GA (AGA) infants, late-onset FGR infants with a CPR below the 5 th percentile had more cognitive deficits at 6-8 years than late-onset FGR infants with a normal CPR (30). Similarly, the TRUFFLE trial, evaluating whether DV waveforms may better guide delivery in early-onset FGR than shortterm variation of fetal heart rate, reported a weak association between abnormal neurodevelopment at 2 years and higher umbilicocerebral ratios (more brain-sparing) at inclusion, but not at one week before delivery (31). They concluded that, in early FGR, brain-sparing is less useful to guide elective delivery (32). Moreover, despite its neuroprotective function, early onset and prolonged brain-sparing in FGR represent a risk factor for poor neurodevelopment.

To our knowledge, this is the first study limited to FGR children reporting equal and even better neurodevelopmental outcomes following brain-sparing, which was contrary to our hypothesis. In the same cohort, however, we previously reported brain-sparing to be associated with abnormal GMs one week after birth, but not at three months post-term (27). Literature suggests that only consistently abnormal GMs until eight weeks postterm are predictive of low IQ later in life (28). Thus, although associated with adverse perinatal outcome, brain-sparing in FGR seems to be beneficial and even critical for long-term neurodevelopment. Our data even suggest that brain-sparing outweighs any benefits a higher GA at birth may have for neurodevelopment, since FGR children without brain-sparing, born at a later GA, experienced more behavior and EF problems than more preterm babies with brain-sparing. However, our findings may also relate to onset of FGR relative to brain development. While the brain requires less oxygen earlier in gestation, the third trimester presents a period of increased brain growth and oxygen demand (33). Early and late onset FGR may therefore differentially affect the brain, as was recently demonstrated in fetal sheep (34). Moreover, the same study demonstrated that fetuses with late-onset FGR become hypoxic faster than fetuses with early-onset FGR. Thus, hypoxia during the last trimester may be more difficult to compensate and more harmful to the brain than at earlier stages, overriding any beneficial effects of advanced GA. Although a reduced CPR would frequently be the first sign of fetal hemodynamic adaptation in late FGR, severely compromised fetuses can show preterminal loss of compensatory cerebral vasoreactivity, which was possibly observed in at least two children without brainsparing and may further explain poorer neurodevelopment in these patients $(8,35)$.

As expected, postnatal cerebral hypoxia negatively affected long-term behavior and EF following FGR. This included $\mathrm{r}_{\mathrm{c}} \mathrm{SO}_{2}$ values below 72\% (postnatal day 1) and 77\% (postnatal day 2) as measured with the neonatal INVOS sensor. Verhagen et al. also report poorer cognition and motor function at 23 years following saturations below $72 \%$ on postnatal day 1 
in preterm AGA infants (20). Interestingly, we observed the opposite for PIQ, which was poorer with saturations above $77 \%$ on day 2. Although Verhagen et al. similarly reported poorer cognition at $\mathrm{r}_{\mathrm{c}} \mathrm{SO}_{2}$ levels above $83 \%$ on day 1 , Verhagen et al. (20) the inverse relationship between $\mathrm{r}_{\mathrm{c}} \mathrm{SO}_{2}$ and PIQ is puzzling. PIQ has, however, been related to motor function, and oxidative stress is known to cause white matter and motor neuron injury, in particular if preceded by hypoxia (36-41). Additionally, hemodynamic redistribution may occur within the brain from frontal regions to basal ganglia in FGR fetuses with brainsparing and impending cardiac failure, as heralded by abnormal DV waveforms (42-44). As our data support an association between fetal decompensation and poorer PIQ, intracerebral perfusional redistribution may indeed contribute to a poorer PIQ in these children. Elective delivery based on DV waveforms in early FGR may therefore benefit neurodevelopment, as suggested by the TRUFFLE study (45). Moreover, brain-sparing was related to high postnatal $\mathrm{r}_{\mathrm{c}} \mathrm{SO}_{2}$, suggesting that the proposed neuroprotective effects of postnatal $\mathrm{r}_{\mathrm{c}} \mathrm{SO}_{2}$ are merely a reflection of preferential (intra)cerebral perfusion. Indeed, brain-sparing seemed to mediate some of the associations between $\mathrm{r}_{\mathrm{c}} \mathrm{SO}_{2}$ and neurodevelopment, but not all. Postnatal events (second hit) influencing brain oxygenation may therefore also be important.

We acknowledge some limitations. First, a high loss to followup and a small sample reduced statistical power. Additionally, some children were unable to perform the WPPSI due to severe cognitive or behavioral problems, further decreasing the power to detect IQ differences. Of note, none of these infants showed fetal brain-sparing and all had low postnatal $\mathrm{r}_{\mathrm{c}} \mathrm{SO}_{2}$, supporting our findings. Second, multiple testing may have introduced type 1 errors and our findings need confirmation by larger cohorts. Third, behavior and EF were assessed using parental questionnaires, and not by actually testing the children. Final, our cohort consisted of a heterogeneous group of term and preterm infants, possibly including FGR of different entities. Although this cohort excluded children with chromosomal abnormalities and placental histologic findings did not significantly differ between FGR children with and without brain-sparing, placental insufficiency may have been less severe in those without fetal brain-sparing.

In conclusion, in this 4-year-old FGR cohort, fetal brainsparing and high postnatal $\mathrm{r}_{\mathrm{c}} \mathrm{SO}_{2}$ were-as a reflection of one and the same mechanism, but also independently-associated with better behavior and EF. Gestational age at onset of FGR relative to cerebral oxygen demands may play a role. However, high $\mathrm{r}_{\mathrm{c}} \mathrm{SO}_{2}$ on day two after birth was also associated with poorer performance IQ, possibly involving intracerebral hemodynamic redistribution upon cardiac decompensation and oxidative stress. Elective delivery based on abnormal DV waveforms indicating

\section{REFERENCES}

1. Miller SL, Huppi PS, Mallard C. The consequences of fetal growth restriction on brain structure and neurodevelopmental outcome. J Physiol (Lond). (2016) 594:807-23. doi: 10.1113/JP2 71402 decline of cardiac function and protective brain-sparing, together with postnatal measures reducing the cerebral hypo- and hyperoxic burden, may benefit long-term neurodevelopment following FGR. Moreover, FGR infants without fetal brainsparing seem to require closer follow-up.

\section{DATA AVAILABILITY STATEMENT}

The datasets generated for this study are available on request to the corresponding author.

\section{ETHICS STATEMENT}

The studies involving human participants were reviewed and approved by Medical Ethical Committee, University Medical Center Groningen. Written informed consent to participate in this study was provided by the participants' legal guardian/next of kin.

\section{AUTHOR CONTRIBUTIONS}

AR conceptualized the study, collected, analyzed and interpreted the data and drafted the first manuscript. JT contributed to study design and acquisition of perinatal data and critically revised the manuscript for its intellectual content. SS contributed to acquisition, analysis and interpretation of the presented data and critically revised the manuscript for its intellectual content. AF and $\mathrm{AH}$ contributed to acquisition and interpretation of followup data and critically revised the manuscript for its intellectual content. MS contributed to analysis and interpretation of placental data and critically revised the manuscript for its intellectual content. CB contributed to study design, collection and interpretation of fetal Doppler data and critically revised the manuscript for its intellectual content. AB, SAS, and EK contributed to study design and interpretation of the data and critically revised the manuscript for its intellectual content. All authors gave final approval of the version to be published and agree to be accountable for all aspects of the work.

\section{FUNDING}

This research project was part of the research program of the Research Institute of Behavioral and Cognitive Neurosciences (BCN), Graduate School of Medical Sciences, University of Groningen, participation in which is financially supported by the Junior Scientific Master Class of the University Medical Center Groningen, University of Groningen, The Netherlands. No grant or sponsor was involved in producing this article.
2. Levine TA, Grunau RE, McAuliffe FM, Pinnamaneni R, Foran A, Alderdice FA. Early childhood neurodevelopment after intrauterine growth restriction: a systematic review. Pediatrics. (2015) 135:126-41. doi: 10.1542/peds.2014-1143

3. Korzeniewski SJ, Allred EN, Joseph RM, Heeren T, Kuban KCK, O'Shea TM, et al. Neurodevelopment at age 10 years of children born $<28$ weeks with fetal growth restriction. Pediatrics. (2017) 140:697. doi: 10.1542/peds.2017-0697 
4. Morsing E, Malova M, Kahn A, Lätt J, Björkman-Burtscher I, Maršál K, et al. Brain volumes and developmental outcome in childhood following fetal growth restriction leading to very preterm birth. Front Physiol. (2018) 9:1583. doi: 10.3389/fphys.2018.01583

5. Nardozza LMM, Caetano ACR, Zamarian ACP, Mazzola JB, Silva CP, Marçal VMG, et al. Fetal growth restriction: current knowledge. Arch Gynecol Obstet. (2017) 295:1061-77. doi: 10.1007/s00404-017-4341-9

6. Spinillo A, Gardella B, Bariselli S, Alfei A, Silini EM, Dal Bello B. Cerebroplacental doppler ratio and placental histopathological features in pregnancies complicated by fetal growth restriction. J Perinat Med. (2014) 42:321-8. doi: 10.1515/jpm-2013-0128

7. Odibo AO, Riddick C, Pare E, Stamilio DM, Macones GA. Cerebroplacental doppler ratio and adverse perinatal outcomes in intrauterine growth restriction: evaluating the impact of using gestational age-specific reference values. J Ultrasound Med. (2005) 24:1223-8. doi: 10.7863/jum.2005.24.9.1223

8. Muresan D, Rotar IC, Stamatian F. The usefulness of fetal doppler evaluation in early versus late onset intrauterine growth restriction. Review of the literature. Med Ultrasonog. (2016) 18:103-9. doi: 10.11152/mu.2013.2066.181.dop

9. Conde-Agudelo A, Villar J, Kennedy SH, Papageorghiou AT. Predictive accuracy of cerebroplacental ratio for adverse perinatal and neurodevelopmental outcomes in suspected fetal growth restriction: systematic review and meta-analysis. Ultrasound Obstet Gynecol. (2018) 52:430-41. doi: 10.1002/uog.19117

10. Roza SJ, Steegers EA, Verburg BO, Jaddoe VW, Moll HA, Hofman A, et al. What is spared by fetal brain-sparing? Fetal circulatory redistribution and behavioral problems in the general population. Am J Epidemiol. (2008) 168:1145-52. doi: 10.1093/aje/kwn233

11. van den Broek, Antonia JM, Kok JH, Houtzager BA, Scherjon SA. Behavioural problems at the age of eleven years in preterm-born children with or without fetal brain sparing: a prospective cohort study. Early Hum Dev. (2010) 86:37984. doi: 10.1016/j.earlhumdev.2010.04.007

12. Leppänen M, Ekholm E, Palo P, Maunu J, Munck P, Parkkola R, et al. Abnormal antenatal doppler velocimetry and cognitive outcome in very-lowbirth-weight infants at 2 years of age. Ultrasound Obstet Gynecol. (2010) 36:178-85. doi: 10.1002/uog.7694

13. Beukers F, Aarnoudse-Moens CS, van Weissenbruch MM, Ganzevoort W, van Goudoever JB, van Wassenaer-Leemhuis AG. Fetal growth restriction with brain sparing: neurocognitive and behavioral outcomes at 12 years of age. $J$ Pediatr. (2017) 188:103-9. e2. doi: 10.1016/j.jpeds.2017.06.003

14. Cohen E, Wong FY, Horne RS, Yiallourou SR. Intrauterine growth restriction: impact on cardiovascular development and function throughout infancy. Pediatr Res. (2016) 79:821-30. doi: 10.1038/pr.2016.24

15. Cohen E, Baerts W, Caicedo Dorado A, Naulaers G, van Bel F, Lemmers PMA. Cerebrovascular autoregulation in preterm fetal growth restricted neonates. Arch Dis Child Fetal Neonatal Ed. (2019) 104:F467-F72. doi: 10.1136/archdischild-2017-313712

16. Verhagen EA, Kooi EM, van den Berg PP, Bos AF. Maternal antihypertensive drugs may influence cerebral oxygen extraction in preterm infants during the first days after birth. J Matern Fetal Neonatal Med. (2013) 26:871-6. doi: 10.3109/14767058.2013.766695

17. Eriksen VR, Hahn GH, Greisen G. Dopamine therapy is associated with impaired cerebral autoregulation in preterm infants. Acta Paediatrica. (2014) 103:1221-6. doi: 10.1111/apa.12817

18. Cohen E, Dix L, Baerts W, Alderliesten T, Lemmers P, van Bel F. Reduction in cerebral oxygenation due to patent ductus arteriosus is pronounced in small-for-Gestational-Age neonates. Neonatology. (2017) 111:126-32. doi: $10.1159 / 000448873$

19. Polavarapu SR, Fitzgerald GD, Contag S, Hoffman SB. Utility of prenatal doppler ultrasound to predict neonatal impaired cerebral autoregulation. $J$ Perinatol. (2018) 38:474-81. doi: 10.1038/s41372-018-0050-x

20. Verhagen EA, Van Braeckel KN, van der Veere CN, Groen H, Dijk $\mathrm{PH}$, Hulzebos $\mathrm{CV}$, et al. Cerebral oxygenation is associated with neurodevelopmental outcome of preterm children at age 2 to 3 years. Dev Med Child Neurol. (2015) 57:449-55. doi: 10.1111/dmcn.12622

21. Yiş U, Kurul SH, Kumral A, Cilaker S, Tugyan K, Genç S, et al. Hyperoxic exposure leads to cell death in the developing brain. Brain Dev. (2008) 30:556-62. doi: 10.1016/j.braindev.2008.01.010
22. DeVore GR. The importance of the cerebroplacental ratio in the evaluation of fetal well-being in sGA and aGA fetuses. Obstet Gynecol. (2015) 213:5-15. doi: 10.1016/j.ajog.2015.05.024

23. Wechsler D. WPPSI-III Technical and Interpretive Manual. Burlington, VT: The Psychological Corporation. (2002).

24. Achenbach T, Rescorla L. Manual for the aSEBA Preschool Forms \& Profiles: An Integrated System of Multi-Informant Assessment; Child Behavior Checklist for Ages 1112-5; Language Development Survey; Caregiver-Teacher Report Form. Burlington: University of Vermont. (2000).

25. Gioia GA, Andrwes K, Isquith PK. Behavior Rating Inventory of Executive Function-Preschool Version (BRIEF-P). Odessa, FL: Psychological Assessment Resources (1996).

26. Tanis JC, Boelen MR, Schmitz DM, Casarella L, van der Laan ME, Bos $\mathrm{AF}$, et al. Correlation between doppler flow patterns in growth-restricted fetuses and neonatal circulation. Ultrasound Obstet Gynecol. (2016) 48:210-6. doi: 10.1002/uog.15744

27. Tanis JC, Schmitz DM, Boelen MR, Casarella L, van den Berg PP, Bilardo $\mathrm{CM}$, et al. Relationship between general movements in neonates who were growth restricted in utero and prenatal doppler flow patterns. Ultrasound Obstet Gynecol. (2016) 48:772-8. doi: 10.1002/uog.15903

28. Bruggink JL, Van Braeckel KN, Bos AF. The early motor repertoire of children born preterm is associated with intelligence at school age. Pediatrics. (2010) 125:e1356-63. doi: 10.1542/peds.2009-2117

29. Korkalainen N, Räsänen J, Kaukola T, Kallankari H, Hallman M, Mäkikallio K. Fetal hemodynamics and adverse outcome in primary school-aged children with fetal growth restriction: a prospective longitudinal study. Acta Obstet Gynecol Scand. (2017) 96:69-77. doi: 10.1111/aogs.13052

30. Bellido-González M, Díaz-López MÁ, López-Criado S, MaldonadoLozano J. Cognitive functioning and academic achievement in children aged 6-8 years, born at term after intrauterine growth restriction and fetal cerebral redistribution. J Pediatr Psychol. (2016) 42:345-54. doi: 10.1016/s0046-8177(00)80241-5

31. Stampalija T, Arabin B, Wolf H, Bilardo CM, Lees C, Brezinka C, et al. Is middle cerebral artery doppler related to neonatal and 2-year infant outcome in early fetal growth restriction? Obstet Gynecol. (2017) 216:521.e1-521.e13. doi: 10.1016/j.ajog.2017.01.001

32. Bilardo CM, Hecher K, Visser GH, Papageorghiou A, Marlow N, Thilaganathan B, et al. Severe fetal growth restriction at 26-32 weeks: key messages from the tRUFFLE study. Ultrasound Obstetr Gynecol. (2017) 50:285-90. doi: 10.1002/uog.18815

33. Dobbing J. The later growth of the brain and its vulnerability. Pediatrics. (1974) 53:2-6.

34. Alves de Alencar Rocha AK, Allison BJ, Yawno T, Polglase GR, Sutherland AE, Malhotra A, et al. Early- versus late-Onset fetal growth restriction differentially affects the development of the fetal sheep brain. Dev Neurosci. (2017) 39:141-55. doi: 10.1159/000456542

35. Cohen E, Baerts W, van Bel F. Brain-Sparing in intrauterine growth restriction: considerations for the neonatologist. Neonatology. (2015) 108:269-76. doi: 10.1159/000438451

36. Chang JL, Bashir M, Santiago C, Farrow K, Fung C, Brown AS, et al. Intrauterine growth restriction and hyperoxia as a cause of white matter injury. Dev Neurosci. (2018) 40:344-57. doi: 10.1159/000494273

37. Reich B, Hoeber D, Bendix I, Felderhoff-Mueser U. Hyperoxia and the immature brain. Dev Neurosci. (2016) 38:311-30. doi: 10.1159/0004 54917

38. Rao SD, Yin HZ, Weiss JH. Disruption of glial glutamate transport by reactive oxygen species produced in motor neurons. J Neurosci. (2003) 23:2627-33. doi: 10.1523/JNEUROSCI.23-07-02627.2003

39. Ravera S, Bartolucci M, Cuccarolo P, Litamè E, Illarcio M, Calzia D, et al. Oxidative stress in myelin sheath: the other face of the extramitochondrial oxidative phosphorylation ability. Free Radic Res. (2015) 49:1156-64. doi: 10.3109/10715762.2015.1050962

40. Torres-Cuevas I, Parra-Llorca A, Sánchez-Illana A, Nuñez-Ramiro A, Kuligowski J, Cháfer-Pericás C, et al. Oxygen and oxidative stress in the perinatal period. Redox biology. (2017) 12:674-81. doi: 10.1016/j.redox.2017.03.011

41. Kopp S, Beckung E, Gillberg C. Developmental coordination disorder and other motor control problems in girls with autism spectrum disorder and/or 
attention-deficit/hyperactivity disorder. Res Dev Disabil. (2010) 31:350-61. doi: 10.1016/j.ridd.2009.09.017

42. Seravalli V, Miller JL, Block-Abraham D, Baschat AA. Ductus venosus doppler in the assessment of fetal cardiovascular health: an updated practical approach. Acta Obstet Gynecol Scand. (2016) 95:635-44. doi: 10.1111 /aogs. 12893

43. Hernandez-Andrade E, Figueroa-Diesel $\mathrm{H}$, Jansson $\mathrm{T}$, Rangel-Nava $\mathrm{H}$, Gratacos E. Changes in regional fetal cerebral blood flow perfusion in relation to hemodynamic deterioration in severely growth-restricted fetuses. Ultrasound Obstetr Gynecol. (2008) 32:71-6. doi: 10.1002/uog.5377

44. Lange N, Froimowitz MP, Bigler ED, Lainhart JE, Brain Development Cooperative Group. Associations between IQ, total and regional brain volumes, and demography in a large normative sample of healthy children and adolescents. Dev Neuropsychol. (2010) 35:296-317. doi: 10.1080/87565641003696833

45. Lees CC, Marlow N, van Wassenaer-Leemhuis A, Arabin B, Bilardo $\mathrm{CM}$, Brezinka C, et al. 2 year neurodevelopmental and intermediate perinatal outcomes in infants with very preterm fetal growth restriction (TRUFFLE): a randomised trial. Lancet. (2015) 385:2162-72. doi: 10.1016/S0140-6736(14)62049-3

46. Lewis SH, Perrin EV. Pathology of the Placenta. Churchill Livingstone. (1999).

47. Khong TY, Bendon RW, Qureshi F, Redline RW, Gould S, Stallmach T, et al. Chronic deciduitis in the placental basal plate: definition and interobserver reliability. Hum Pathol. (2000) 31:292-5. doi: 10.1016/S0046-8177(00)80241-5

48. Redline RW, Faye-Petersen O, Heller D, Qureshi F, Savell V, Vogler $\mathrm{C}$, et al. Amniotic infection syndrome: nosology and reproducibility of placental reaction patterns. Pediatr Dev Pathol. (2003) 6:435-48. doi: 10.1007/s10024-003-7070-y

49. Redline RW, Ariel I, Baergen RN, Derek J, Kraus FT, Roberts DJ, et al. Fetal vascular obstructive lesions: nosology and reproducibility of placental reaction patterns. Pediatr Dev Pathol. (2004) 7:443-52. doi: 10.1007/s10024-004-2020-x

50. Redline RW, Boyd T, Campbell V, Hyde S, Kaplan C, Khong TY, et al. Maternal vascular underperfusion: nosology and reproducibility of placental reaction patterns. Pediatr Dev Pathol. (2004) 7:237-49. doi: $10.1007 / \mathrm{s} 10024-003-8083-2$
51. Redline RW. Inflammatory responses in the placenta and umbilical cord. Sem Fetal Neonat Med. (2006). 11:296-301. doi: 10.1016/j.siny.2006. 02.011

52. Redline RW. Villitis of unknown etiology: noninfectious chronic villitis in the placenta. Hum Pathol. (2007) 38:1439-46. doi: 10.1016/j.humpath.2007.05.025

53. Redline RW. Elevated circulating fetal nucleated red blood cells and placental pathology in term infants who develop cerebral palsy. Hum Pathol. (2008) 39:1378-84. doi: 10.1016/j.humpath.2008. 01.017

54. Roberts DJ, Post MD. The placenta in pre-eclampsia and intrauterine growth restriction. J Clin Pathol. (2008) 61:1254-60. doi: 10.1136/jcp.2008. 055236

55. Pathak S, Lees CC, Hackett G, Jessop F, Sebire NJ. Frequency and clinical significance of placental histological lesions in an unselected population at or near term. Virchows Archiv. (2011) 459:565-72. doi: 10.1007/s00428-011-1157-z

56. Bendon RW. Review of autopsies of stillborn infants with retroplacental hematoma or hemorrhage. Pediatr Dev Pathol. (2011) 14:10-5. doi: 10.2350/10-03-0803-OA.1

57. Stevens D, Al-Nasiry S, Bulten J, Spaanderman M. Decidual vasculopathy in preeclampsia: lesion characteristics relate to disease severity and perinatal outcome. Placenta. (2013) 34:805-9. doi: 10.1016/j.placenta.2013. 05.008

Conflict of Interest: The authors declare that the research was conducted in the absence of any commercial or financial relationships that could be construed as a potential conflict of interest.

Copyright (c) 2020 Richter, Salavati, Kooi, Heijer, Foreman, Schoots, Bilardo, Scherjon, Tanis and Bos. This is an open-access article distributed under the terms of the Creative Commons Attribution License (CC BY). The use, distribution or reproduction in other forums is permitted, provided the original author(s) and the copyright owner(s) are credited and that the original publication in this journal is cited, in accordance with accepted academic practice. No use, distribution or reproduction is permitted which does not comply with these terms. 